\title{
BACK CALCULATION DETERMINATION OF THE MODULUS ELASTICITY OF LIMESTONE ROCK BASED ON PRESSUREMETER TEST DATA
}

\author{
Yusep Muslih Purwana ${ }^{1}$, Akbar Dwi Anggoro ${ }^{1}$, Niken Silmi Surjandari ${ }^{1}$, dan Pontjo Utomo ${ }^{2}$ \\ ${ }^{1}$ Civil Engineering Department, Sebelas Maret University, Jl. Ir. Sutami 36 A Surakarta \\ ${ }^{2} \mathrm{Oz}$ Goes PTY, Australia \\ Email ${ }^{1}$ ymuslih@yahoo.com \\ Email²: anggoroakbar@gmail.com \\ Email ${ }^{3}$ : nikensilmisurjandari@gmail.com \\ Email':pontjo71@gmail.com
}

\begin{abstract}
Pressuremeter Test (PMT) is an in situ method of soil investigation that is used to determine the pressure and strain behavior of the soil or rock. At pseudo-elastic phase, this behavior can be described by the PMT's output parameter, modulus presurremeter (ЕРMT). It has been realized for a long time that EPMT cannot be used directly to describe modulus elasticity (E) from the ground so a correction is needed. Menard and Rousseau suggested that Menard's $\alpha$ Factor be used to correct the value of $\mathrm{E}_{\mathrm{PMT}}$ that determined empirically according to soil type, density conditions, and deformation behavior of soil or rock when given pressure (rheological properties). Therefore, it is necessary to study PMT behavior along with Menard's $\alpha$ Factor values in a variety of more specific sample types. In this study Back Calculation will be performed on the value of $E$ from PMT testing on limestone sedimentary rocks by remodeling PMT using Finite Element Method (FEM). Back Calculation is a mathematical recalculation process of estimating the value of a data from an event along with related parameters. The results of the study show that there is a good correlation between the modulus of elasticity of the results of PMT and the modulus of elasticity of the Back Calculation. Menard correction factor in this study is consistent with the results of previous research that is equal to 0.47 where this value increases with the increase in the depth of the test sample.
\end{abstract}

Keywords: Back calculation, pressuremeter, modulus elasticity, limestone

\section{INTRODUCTION}

Pressuremeter Test (PMT) is one of the geotechnical testing equipment in the field to obtain the modulus of elasticity parameters. According to Gambin (1990), PMT was first put forward by Kogler in 1930 but has not been able to operate properly so that this technology was abandoned. Menard from France in 1954 took back the idea of Kloger and improved his working principle so that it became a popular and world-known method. More than 300,000 buildings have been designed with PMT data and in 1972 all bridges and flyovers in France were designed using PMT data.

The purpose of this study is to re-model PMT to do Back Calculation of modulus elasticity on limestone sedimentary rocks on the Bahrain island. Back calculation aims to compare the output of the pressuremeter modulus $\left(\mathrm{E}_{\mathrm{PMT}}\right)$ with the modulus elasticity of rock $(\mathrm{E})$ using a mathematical approach to FEM to produce Menard's $\alpha$ factor that can be used as a correction value in the analysis of the results of PMT testing at limestone rock.

\section{Pressuremeter Test}

Pressuremeter Test (PMT) is an in situ test used to determine soil or rock characteristics. PMT utilizes a probe that is inserted into the borehole according to the depth of the ground test that be observed. The probe is a flexible membrane that can be blown and expand to provide pressure on the borehole wall so the soil or rock will be deformed. The relationship curve of the addition of pressure with lateral deformation of the soil is then used as the basis for the analysis of the test results of PMT. 


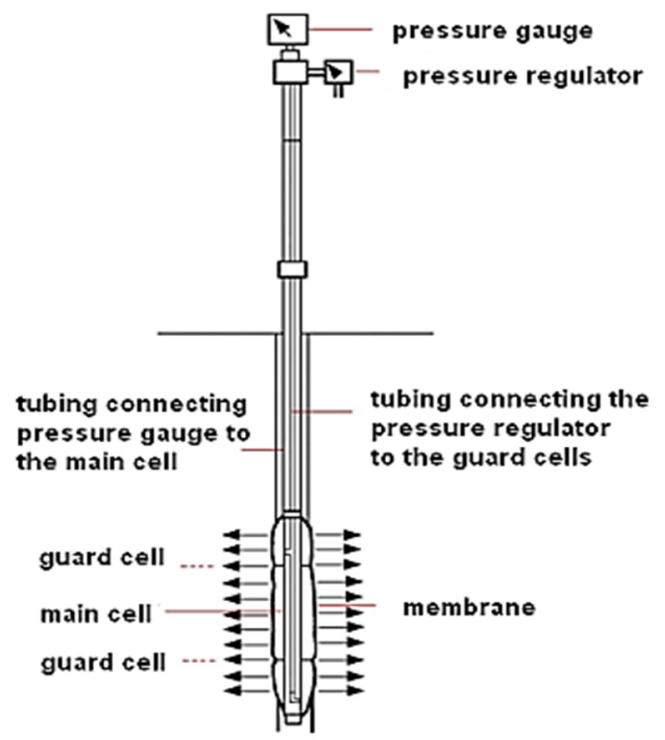

Figure 1. Sketch of the Menard Pressuremeter test instrument Baguelin et al. (1978)

Various studies have been carried out in validate test results from PMT. One of the problems is by remodeling PMT mathematically using the FEM approach in the analysis of behavior and regulation of the land. Some researchers who conducted PMT modeling with FEM were Yeung and Carter (1987) as modeling PMT on clay and sand soil which demonstrated the overestimates of strength parameters from the use of simplified onedimensional interpretation of the test data, Rita (2008) on miocenic sandy soil in Lisbon which found that the disruption in field at PMT test had a significant effect in the comparison with modeling results and sugested to do preboring PMT as a comparison, Abed et al (2013) conducted a review of changes in input parameters in FEM modeling of PMT where using the Press-Sim program on granular samples, and Balachandran (2016) in galtial sedimentary rocks in Toronto which do verification of gheometry modeling of PMT and a comparison of the results of PMT and SPT, he found that PMT and SPT have a good correlation. In addition, there was also the modeling of data by PMT by Barhmi et all (2014) as a trigger for PMT loading on Symen 1D program with Plaxis $2 \mathrm{D}$.

\section{Calibration of Pressuremeter Test}

The calibration process in PMT testing is highly emphasized. The relationship curve of the soil pressures of the actual PMT can only be calculated if the value of pressure and volume lost during the testing process can be known. The purpose of the calibration process is to calculate the value of the pressure and volume lost so that the real stress deformation behavior of the soil can be obtained.

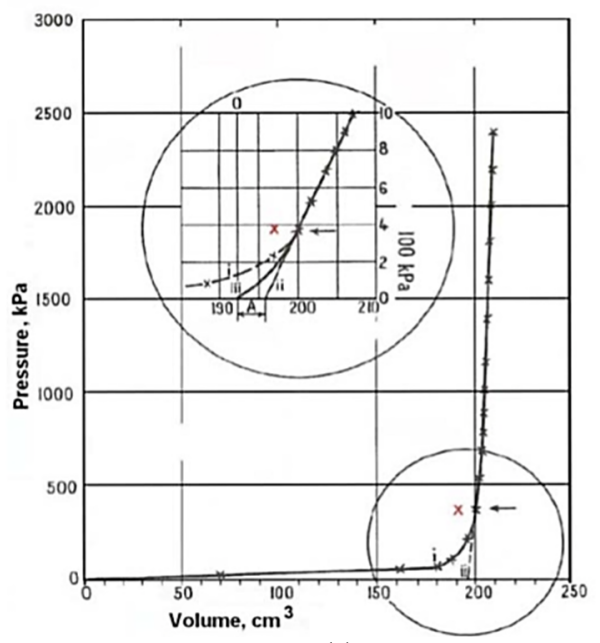

(a)

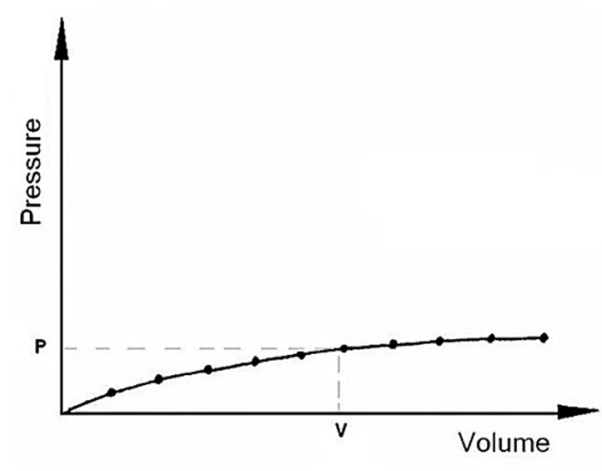

(b)

Figure 2. Calibration Curve, Baguelin et al. (1978) (a) and Pressure Loss, Briaud (1992) (b)

Calibration is carried out by inserting a probe in a thick-walled steel calibration tube. The pressure is increased gradually from $100 \mathrm{kPa}$ until the membrane is in contact with the tube than increased to $300 \mathrm{kPa}$ until reach 
maximum pressure. Each step of the pressure is given a duration of 1 minute and volume is read to get a volume calibration curve, as shown in figure 2 (a). Calibration of pressure loss in the figure 2 (b) is needed because the pressure that applied to the probe must overcome membrane resistance. The probe is placed vertically on the ground surface and then pumped slowly until it reaches the maximum working volume. Each step of the pressure is maintained for 1 minute and the volume reading is carried out every 15 seconds.

\section{Interpretation and Result of Pressuremeter Test}

The interpretation of PMT can be presented in graphical form that shows the relationship between the volume and pressure applied along with the correction of the test. The pressure value read during the test is lower than the actual pressure applied because of the hydrostatic pressure of the water in the pipe and the membrane resistance. The volume value obtained during the test is higher than the actual value due to compressed water in the circuit.

There are 3 phases in PMT as shown in Figure 3. The initial part (1) of the curve shows the development of the membrane to the full wall of the drill hole. The endpoint of this phase corresponds to the values, considers the conditions of ground break, and marks the theoretical start of the test. The second phase (2) is called the pseudoelastic phase and during this test part the soil is considered to be in a small deformation domain. The point of transition to the next phase represents the point of creep. In the last phase (3) soil is in a plastic condition.

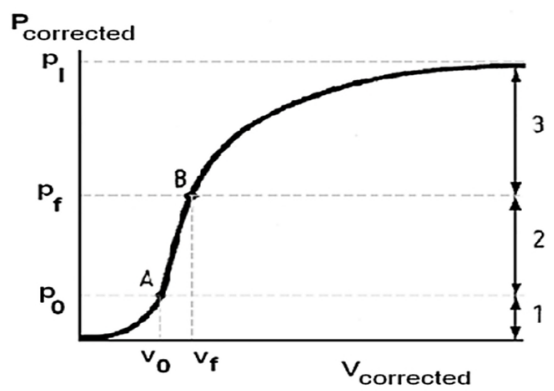

Fig. 3. Typical Curves and Phases of the Presuremeter Test

The $E_{\text {PMT }}$ value is a derivative of the Shear Modulus value $(G)$ which can be obtained from the following equation:

$$
G=V x \Delta p / \Delta V
$$

Shear modulus can be converted into modulus pressuremeter, EPMT by using this formula:

$$
G=E_{P M T} /(2(1+V))
$$

Get a new equation by entering equation 2.20 in equation 2.21 , being:

$$
E=2(1+v) V \Delta p / \Delta V
$$

where $\mathrm{V}$ is the volume of the cylinder in the middle between points $\mathrm{A}$ and $\mathrm{B}, \Delta \mathrm{p}$ is the change in pressure in the plastic zone, $\Delta \mathrm{V}$ is the change in volume in the plastic zone.

\section{Menard's $\alpha$ Factor}

The difference between the pressuremeter modulus ( $\left.\mathrm{E}_{\mathrm{PMT}}\right)$ value and the modulus of soil elasticity (E) has been realized for a long time. As stated by Briaud (1992), Menard and Rousseau realized that the use of $E_{\text {PMT }}$ as a modulus of soil elasticity in predicting a decrease in foundation results in a value that is always greater than the measurement of actual decline.

Menard and Rousseau suggested that a correction factor be used which later became known as Menard's $\alpha$ Factor to assist in predicting the response of the soil when given a more accurate load, so that the following equation was obtained:

$$
\alpha=E_{P M T} / E
$$

The value of $\alpha$ is determined empirically according to soil type, density conditions, and deformation behavior when given pressure (rheological properties). According to Briaud (1992) several reasons that contribute to the differences of $\mathrm{E}_{\mathrm{PMT}}$ and $\mathrm{E}$ is the two modulus are measured in the huge range of radial length differences; the presence of stress near the borehole wall can cause degradation of the average 
elastic modulus; the presence of soil disturbances due to drilling and installation of probes around the borehole wall; Calculation of the modulus value assumes that the cylinder length is infinite while the reality is not; PMT testing uses a load pattern that lasts for several minutes while the foundation lasts for a longer time; the presence of an anisotropy condition allows the measured horizontal modulus values to differ from the vertical modulus required in the decrease analysis.

\section{METHODOLOGY}

\section{Location Map}

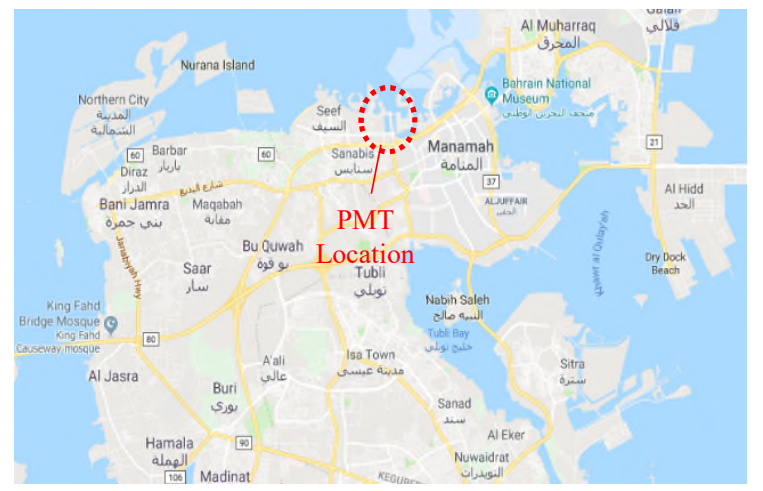

Fig. 4. PMT Testing Location (Google Maps)

The location of PMT testing in this study was located on northern Bahrain Island. This place is a shallow sea which is then reclaimed. The formation of Bahrain Island is generally dominated by sediments of old Eocene. PMT testing at this location was carried out on limestone sedimentary rock formations with the condition is highly to slightly weathered. Soil conditions at locations ranging from ground level to around $6.00-8.00 \mathrm{~m}$ are dominated by carbonate sand with gravel-sized shells and shell fragments, followed by about 2.00 to $5.00 \mathrm{~m}$ thick layers of calcarenit (carbonate sandstone). This carbonate rock spreads a layer of calcisiltite (carbonate siltstone) with a thickness of about 1.50 to $2.00 \mathrm{~m}$. Below this siltstone carbonate layer, the thickness of the carbonate mudstone is about 10 to $17 \mathrm{~m}$. Limestone crystalline rock layers start at around 30 to $35 \mathrm{~m}$ below the existing soil surface.

\section{Pressuremeter Testing}

The process of drilling use a DANDO 250 rig. The pressuremeter test distance interval is about $2.5 \mathrm{~m}$ in each borehole. PWF core bits are used with an outer diameter of about $120 \mathrm{~mm}$ in the first one-meter-deep drilling, while for the next $1.5 \mathrm{~m}$ using NX core bit the outer diameter is about $76 \mathrm{~mm}$. The pressuremeter device used is OYO Elastmeter-2, OYO Corp product, Japan with a length of rubber probe (L) $520 \mathrm{~mm}$, outer diameter (D) 70 $\mathrm{mm}$ and a ratio of $\mathrm{L} / \mathrm{D}$ probes around 7 . The maximum pressure capacity that a hand pump can provide is 20 $\mathrm{MPa}$, while the maximum radial displacement that can be read is $10 \mathrm{~mm}$. The pressuremeter test is carried out after the probe is inserted into the drill hole at the specified depth. Pressure is applied by increasing the pressure step by step, with an increase of $0.25 \mathrm{MPa}$ and $0.5 \mathrm{MPa}$ for claystone and limestone formations. Each pressure increase will be kept constant for 1 minute. The reading of the drill hole wall displacement is carried out for 30 seconds and 1 minute.

\section{Pressuremeter Modelling}

PMT was modeled with FEM through the Plaxis 2D program using the axisymetri principle. Axisymetri is a cylindrical model where the $\mathrm{z}$ axis (vertical) are made into a rotary shaft. A review of soil behavior was carried out by modeling the pressure of the PMT probe by applying lateral pressure to the soil so that it results in deformation of the borehole wall. Variations in lateral loading were given according to the capacity of PMT test equipment. There were 7 stages of loading in this study, namely $0,3,6,9,12,15$, and $18 \mathrm{MPa}$. Deformation results at each loading stage, then presented into curves. This study adopted the geometry used by Levasseur et all (2009) with some modification by adding loads of overburden and borehole dimension adjustment as shown in Figure 5. 


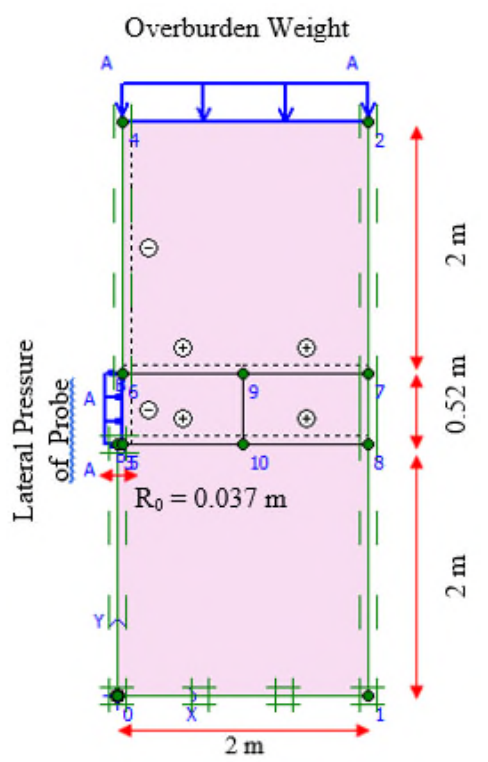

Figure 5. Modeling Geometry in Study

The undrained parameters were used in this study such as modulus of soil elasticity (E), undrained shear strength $\left(C_{U}\right)$, soil specific gravity $(\gamma)$, Poison's ratio $(v)=0.30$ and lateral soil pressure $(K 0)=0.429$. The E value will be searched through the FEM experiment so that the naming is replaced with $\mathrm{E}_{\mathrm{FEM}}$ while the $\mathrm{C}_{\mathrm{U}}$ value and $\gamma$ are taken based on the results of laboratory testing. $v$ value was an estimate of the limestone soil parameter value while $\mathrm{K}_{0}$ was calculated using the Terzaghi equation as follows:

$$
K_{0}=v /(1-v)
$$

The natural pressure of the rock is modeled by giving a uniform load as the overburden load depiction adjusts to the weight of the rock content $(\gamma)$ along with the depth of the PMT (H) test point minus the length of the modeling geometry limit $(2 \mathrm{~m})$.

$$
P=\gamma(H-2)
$$

The borehole wall was given a clamped joint to prevent deformation. Especially in the area around the probe, the pinch joint was replaced by the lateral load calculated by Rankine's theory with the following equation:

$$
P_{0}=1 / 2 K_{0} \gamma_{\text {sat }} H
$$

The PMT curve than presented in the form of pressure and volume of the probe. The probe volume was calculated using a general formula $V=\pi R 2 t$, where $R$ is the length of the total radius of the probe when it expands, and $t$ is the height of the probe. The value of $R$ can be calculated from the sum of the probe radius before loading $\left(R_{0}\right)$ with the lateral deformation $(r)$ as the following equation:

$$
R=R_{0}+r
$$

Analysis of soil elasticity modulus value, E was taken from $\mathrm{E}_{\mathrm{FEM}}$ values from modeling results that produce curves that approach field PMT testing. The trial was conducted four times in entering the EFEM parameter input value in Plaxis 2D modeling. This aims to determine the relationship between $\mathrm{E}_{\mathrm{FEM}}$ values and EPMT. According to Sedran et al (2013) the relationship curve will form linear equations with functions $E_{\mathrm{FEM}}=\mathrm{a}+\mathrm{b} \mathrm{E}_{\mathrm{PMT}}$ as shown in Figure 6 by using estimation below:

Trial $1 \mathrm{E}_{\mathrm{FEM}}= \pm 1 / 2 \times \mathrm{E}_{\mathrm{PMT}}$

Trial $3 \mathrm{E}_{\mathrm{FEM}}= \pm 5 / 3 \times \mathrm{E}_{\mathrm{PMT}}$
Trial 2, $\mathrm{E}_{\mathrm{FEM}}= \pm 2 / 3 \times \mathrm{E}_{\mathrm{PMT}}$

Trial $4, \mathrm{E}_{\mathrm{FEM}}= \pm 11 / 2 \times \mathrm{E}_{\mathrm{PMT}}$ 


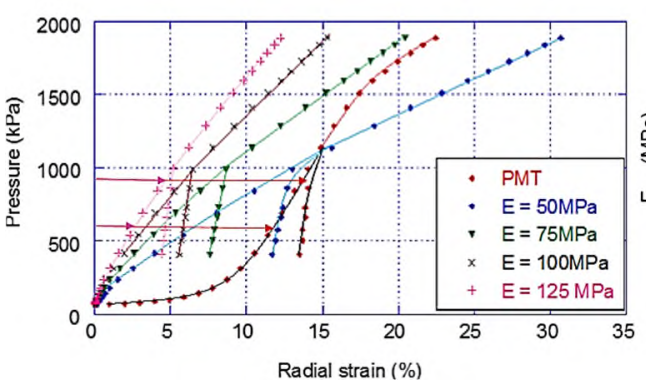

(a)

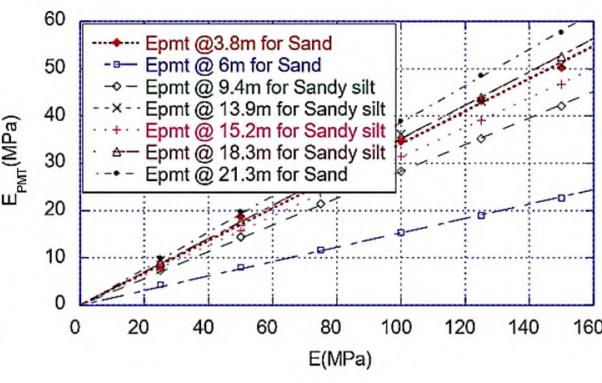

(b)

Figure 6. Pressure and Strain Curves (a) and Relations Curves of Eрмт and EFEм (Balachandran, 2016)

The next stage is to analyze Menard's value a factor that was a quotient of the $\mathrm{E}_{\mathrm{PMT}}$ value by $\mathrm{E}_{\mathrm{FEM}}$. In addition, a review of the effects of the depth of PMT test points on Menard's value is a factor in limestone sedimentary rocks. PMT data recording on all boreholes can be recapitulated as one because the type of soil that observed have the same characteristics.

\section{RESULT AND DISCUSSION}

\section{Model Input Parameters}

PMT modeling was carried out at test points BH 01, BH02, and BH03 with variations in depth of $17-67 \mathrm{~m}$. Typical samples that exist in these locations are the same, namely limestone sedimentary rocks with very varied strength levels with EРмT values ranging from 400 - $5900 \mathrm{MPa}$. Following is the recapitulation of input parameters:

Table 1. BH 01 models input parameters

\begin{tabular}{ccccc}
\hline $\begin{array}{c}\text { Depth } \\
(\mathrm{m})\end{array}$ & $\begin{array}{c}\text { EPMT }_{\text {PMa }} \\
(\mathrm{MPa})\end{array}$ & $\begin{array}{c}\mathrm{C}_{\mathrm{U}} \\
(\mathrm{MPa})\end{array}$ & $\begin{array}{c}\text { vertical weight } \\
(\mathrm{MPa})\end{array}$ & $\begin{array}{c}\text { lateral weight } \\
(\mathrm{MPa})\end{array}$ \\
\hline 37.45 & 437 & 12.20 & 0.636 & 0.288 \\
44.95 & 3303 & 7.07 & 0.771 & 0.346 \\
47.45 & 1629 & 8.00 & 0.816 & 0.365 \\
49.85 & 3307 & 7.40 & 0.859 & 0.384 \\
52.35 & 4465 & 7.15 & 0.904 & 0.403 \\
54.8 & 4199 & 11.12 & 0.948 & 0.422 \\
58.48 & 1397 & 16.00 & 1.014 & 0.45 \\
62.15 & 1518 & 6.15 & 1.08 & 0.479 \\
65 & 1793 & 10.20 & 1.131 & 0.501 \\
66.9 & 1539 & 7.00 & 1.165 & 0.515 \\
\hline$\gamma_{\text {bulk }}$ & $0.021 \mathrm{MN} / \mathrm{m}^{3}$ & $v$ & 0.3 \\
$\gamma_{\text {dry }}$ & $0.018 \mathrm{MN} / \mathrm{m}^{3}$ & $\mathrm{k} 0$ & 0.429 \\
\hline
\end{tabular}


Table 2. BH 02 models input parameters

\begin{tabular}{ccccc}
\hline $\begin{array}{c}\text { Depth } \\
(\mathrm{m})\end{array}$ & $\begin{array}{c}\mathrm{E}_{\mathrm{PMT}} \\
(\mathrm{MPa})\end{array}$ & $\begin{array}{c}\mathrm{C}_{\mathrm{U}} \\
(\mathrm{MPa})\end{array}$ & $\begin{array}{c}\text { vertical weight } \\
(\mathrm{MPa})\end{array}$ & $\begin{array}{c}\text { lateral weight } \\
(\mathrm{MPa})\end{array}$ \\
\hline 17.08 & 693 & 5.2 & 0.255 & 0.124 \\
27.13 & 985 & 4.3 & 0.424 & 0.197 \\
29.83 & 1806 & 9 & 0.470 & 0.216 \\
34.23 & 5954 & 14 & 0.544 & 0.248 \\
38.85 & 4019 & 7.6 & 0.622 & 0.282 \\
41.75 & 1676 & 7.67 & 0.671 & 0.303 \\
44.35 & 566 & 3.4 & 0.715 & 0.321 \\
46.75 & 1368 & 9.42 & 0.756 & 0.339 \\
49.43 & 852 & 5.57 & 0.801 & 0.358 \\
51.63 & 1244 & 8.55 & 0.838 & 0.374 \\
54.23 & 1609 & 6.14 & 0.882 & 0.393 \\
56.93 & 1538 & 11.32 & 0.928 & 0.413 \\
\hline$\gamma_{\text {bulk }}$ & $0.020 \mathrm{MN} / \mathrm{m} 3$ & $v$ & 0.30 \\
$\gamma_{\text {dry }}$ & $0.017 \mathrm{MN} / \mathrm{m} 3$ & $\mathrm{k}_{0}$ & 0.429 \\
\hline \multicolumn{5}{c}{}
\end{tabular}

Table 3. BH 03 model input parameters

\begin{tabular}{ccccc}
\hline $\begin{array}{c}\text { Depth } \\
(\mathrm{m})\end{array}$ & $\begin{array}{c}\mathrm{E}_{\mathrm{PMT}} \\
(\mathrm{MPa})\end{array}$ & $\begin{array}{c}\mathrm{C}_{\mathrm{U}} \\
(\mathrm{MPa})\end{array}$ & $\begin{array}{c}\text { vertical weight } \\
(\mathrm{MPa})\end{array}$ & $\begin{array}{c}\text { lateral weight } \\
(\mathrm{MPa})\end{array}$ \\
\hline 32.5 & 1361 & 15.5 & 0.548 & 0.25 \\
38.1 & 551 & 4.4 & 0.648 & 0.293 \\
41 & 4503 & 7.1 & 0.7 & 0.316 \\
47.5 & 445 & 1.82 & 0.817 & 0.39 \\
50.6 & 924 & 8.7 & 0.873 & 0.408 \\
53 & 3717 & 14.11 & 0.916 & 0.393 \\
58.3 & 2892 & 10 & 1.011 & 0.449 \\
\hline$\gamma_{\text {bulk }}$ & $0.020 \mathrm{MN} / \mathrm{m} 3$ & $v$ & 0.3 \\
$\gamma_{\text {dry }}$ & $0.018 \mathrm{MN} / \mathrm{m} 3$ & $\mathrm{k}_{0}$ & 0.429 \\
\hline
\end{tabular}

Determination of the size of the vertical and lateral loads adjusted by $\gamma$ rock taken based on the average value of the results of water content testing. The value of $\gamma$ at each test point in the same borehole is considered uniform to facilitate the modeling process. This is because the variation in value $\gamma$ gives a relatively small effect compared to the lateral pressure of the probe. The value of $\gamma$ affects the overburden load and lateral stress in the range of 0.2 - 1.2 $\mathrm{MPa}$ for overburden and $0.1-0.5 \mathrm{MPa}$ for lateral load while the modeled lateral pressure of the probe ranges from 3 - $18 \mathrm{MPa}$.

\section{Pressuremeter Modelling Result}

Modeling analysis was carried out at all test points as presented in chapters 4.1, 4.2, and 4.3. All test points were given lateral loads of probes that were increased with values of $0,3,6,9,12,15$ to $18 \mathrm{MPa}$. The following is an example of the modeling results in the PMT BH 02 test with a depth of $37.45 \mathrm{~m}$ :

The amount of value given in the experiment or trial $\mathrm{E}_{\mathrm{FEM}}$ input was calculated based on rounding the calculated results from equation 7 for finding the relationship between the $E_{P M T}$ value and $E_{\text {FEM. }}$ So that the corresponding EFEM value estimates can be obtained as follows:

$$
\begin{array}{ll}
\text { Trial } 1 \mathrm{E}_{\mathrm{FEM}}=400 \mathrm{MPa}, & \text { Trial } 2 \mathrm{E}_{\mathrm{FEM}}=600 \mathrm{MPa} \\
\text { Trial } 3 \mathrm{E}_{\mathrm{FEM}}=1500 \mathrm{MPa}, & \text { Trial } 4 \mathrm{E}_{\mathrm{FEM}}=2000 \mathrm{MPa}
\end{array}
$$

The following is a diagram of the deformation results in one of the trial input EFEM values on the BH 02 PMT test point modeling $(37.45 \mathrm{~m})$ : 


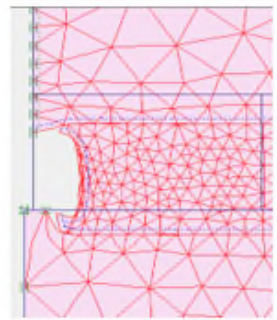

(a)

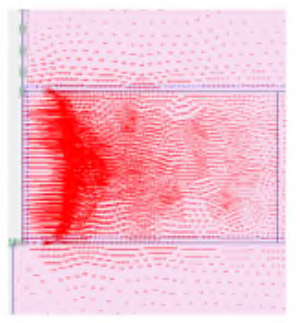

(b)

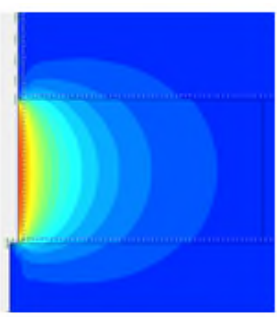

(c)

Figure 7. Mesh Diagram (a) Arrow Diagram (b) and Color Diagram (c) of Horizontal Displacement at loading the stage of BH $02(37.45 \mathrm{~m})($ Test 1, EFEM $=400 \mathrm{MPa})$

Figure 7 shows that giving additional lateral load probes successfully gives deformation to the rock with a slightly concave shape on the edge. This basin was caused by the existence of pinch joints near the location. Determination of the $\mathrm{r}$ value was taken from the length of the maximum deformation produced by the modeling.

A correction was needed to the value of the length of initial radius of the probe (R0) from the modeling curve, ie the value at which the probe enters phase 2 . This can be determined from the R0 value of the pressure curve and probe radius in the field PMT by drawing straight lines on zone 2 to intersect with the $y=0$ axis as shown in figure 8 .

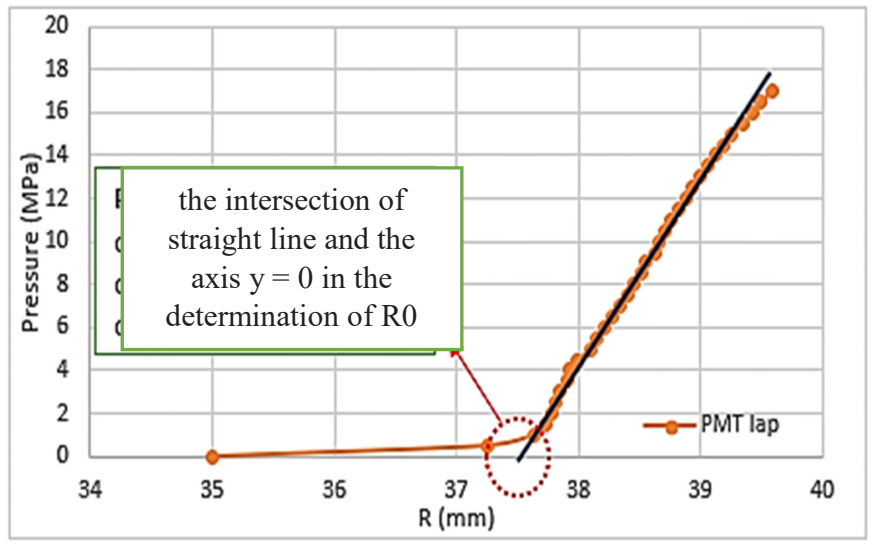

Figure 8. Determination of R0 value in the BH 02 field curve $(37.45 \mathrm{~m})$

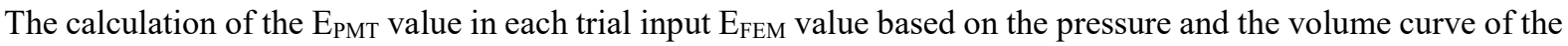
PMT modeling results using equation 2 so that the values are as shown in table 4 . This value is then presented in graphical form to obtain an equation as shown in figure 9.

Table 4 Recapitulation EPMT Modelling

\begin{tabular}{cc}
\hline$E_{\text {FEM }}$ & $\begin{array}{c}\text { EPMT } \\
(\mathrm{MPa})\end{array}$ \\
\hline 37.45 & 437 \\
44.95 & 3303 \\
47.45 & 1629 \\
49.85 & 3307 \\
\hline
\end{tabular}

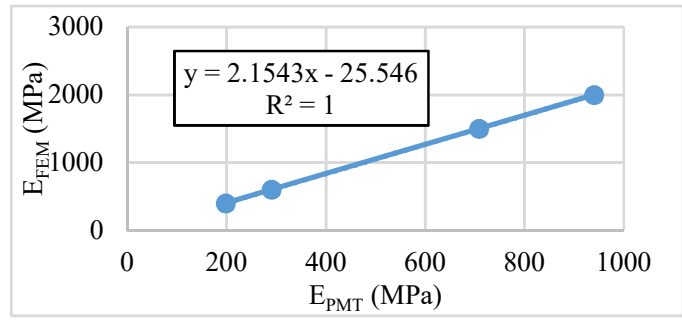

Figure 9 curve generated for the estimation of EFEM value

The equation in figure 8 was then used in calculating the $\mathrm{E}_{\mathrm{FEM}}$ value so that a curve can be generated that matches the field PMT test with an EPMT value of $437 \mathrm{MPa}$. Based on the equation, the EFEM value is $915,88 \mathrm{MPa}$ to be used as the next input value experiment. Figure 10 shows that the curve generated from the EFEM value estimation of the equation is close enough to the results of the PMT test. 


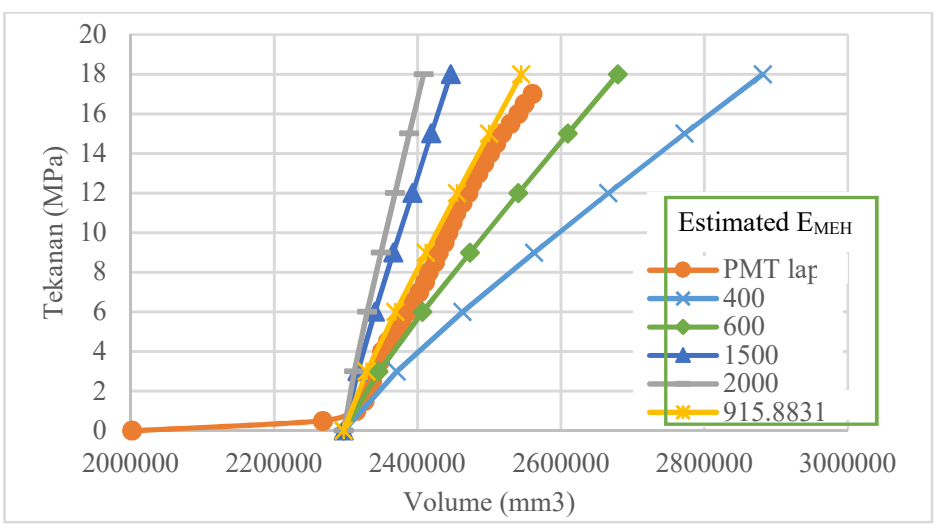

Figure 10. Curve generated from the estimation of EFEM value to the results of the PMT test.

\section{Analisys of Menard's $\alpha$ Factor Value}

Menard's value a factor was calculated from the distribution of $\mathrm{E}_{\mathrm{PMT}}$ values with $\mathrm{E}_{\mathrm{FEM}}$. Menard's value a factor at all test points was calculated then recapitulated into one. Considering that the review soil tested was the same, it can be calculated the average Menard's value factor generated from a sample of limestone sedimentary rocks. Following is the recapitulation of the equation of modulus elasticity and Menard's $\alpha$ factor:

Table 5. Modulus elasticity equation and Menard's $\alpha$ factor BH 01

\begin{tabular}{ccc}
\hline $\begin{array}{c}\text { Depth } \\
(\mathrm{m})\end{array}$ & Equation & $\begin{array}{c}\alpha \text { Menard } \\
\left(\mathrm{E}_{\mathrm{PMT}} / \mathrm{E}_{\mathrm{MEH}}\right)\end{array}$ \\
\hline 37.45 & $\mathrm{E}_{\mathrm{MEH}}=2.096 \mathrm{E}_{\mathrm{PMT}}$ & 0.477 \\
44.95 & $\mathrm{E}_{\mathrm{MEH}}=2.203 \mathrm{E}_{\text {PMT }}$ & 0.454 \\
47.45 & $\mathrm{E}_{\mathrm{MEH}}=2.086 \mathrm{E}_{\text {PMT }}$ & 0.479 \\
49.85 & $\mathrm{E}_{\mathrm{MEH}}=2.099 \mathrm{E}_{\mathrm{PMT}}$ & 0.477 \\
52.35 & $\mathrm{E}_{\mathrm{MEH}}=2.080 \mathrm{E}_{\text {PMT }}$ & 0.481 \\
54.80 & $\mathrm{E}_{\mathrm{MEH}}=2.078 \mathrm{E}_{\text {PMT }}$ & 0.481 \\
58.48 & $\mathrm{E}_{\mathrm{MEH}}=2.050 \mathrm{E}_{\mathrm{PMT}}$ & 0.488 \\
62.15 & $\mathrm{E}_{\mathrm{MEH}}=2.033 \mathrm{E}_{\text {PMT }}$ & 0.492 \\
65.00 & $\mathrm{E}_{\mathrm{MEH}}=2.040 \mathrm{E}_{\text {PMT }}$ & 0.490 \\
66.90 & $\mathrm{E}_{\mathrm{MEH}}=2.013 \mathrm{E}_{\text {PMT }}$ & 0.497 \\
\hline
\end{tabular}

Table 7. Modulus elasticity equation and Menard's $\alpha$ factor BH 03

\begin{tabular}{ccc}
\hline $\begin{array}{c}\text { Depth } \\
(\mathrm{m})\end{array}$ & Equation & $\begin{array}{c}\alpha \text { Menard } \\
\left(\mathrm{E}_{\mathrm{PMT}} / \mathrm{E}_{\mathrm{MEH}}\right)\end{array}$ \\
\hline 32.50 & $\mathrm{E}_{\mathrm{MEH}}=2.054 \mathrm{E}_{\mathrm{PMT}}$ & 0.468 \\
38.10 & $\mathrm{E}_{\mathrm{MEH}}=2.161 \mathrm{E}_{\mathrm{PMT}}$ & 0.477 \\
41.00 & $\mathrm{E}_{\mathrm{MEH}}=2.154 \mathrm{E}_{\mathrm{PMT}}$ & 0.472 \\
50.60 & $\mathrm{E}_{\mathrm{MEH}}=2.156 \mathrm{E}_{\mathrm{PMT}}$ & 0.484 \\
53.00 & $\mathrm{E}_{\mathrm{MEH}}=2.142 \mathrm{E}_{\mathrm{PMT}}$ & 0.484 \\
58.30 & $\mathrm{E}_{\mathrm{MEH}}=2.114 \mathrm{E}_{\mathrm{PMT}}$ & 0.487 \\
\hline
\end{tabular}

Table 6. Modulus elasticity equation and Menard's $\alpha$ factor BH 02

\begin{tabular}{ccc}
\hline $\begin{array}{c}\text { Depth } \\
(\mathrm{m})\end{array}$ & Equation & $\begin{array}{c}\alpha \text { Menard } \\
\left(\mathrm{E}_{\mathrm{PMT}} / \mathrm{E}_{\mathrm{MEH}}\right)\end{array}$ \\
\hline 17.08 & $\mathrm{E}_{\mathrm{MEH}}=2.054 \mathrm{E}_{\mathrm{PMT}}$ & 0.487 \\
27.13 & $\mathrm{E}_{\mathrm{MEH}}=2.161 \mathrm{E}_{\mathrm{PMT}}$ & 0.463 \\
29.83 & $\mathrm{E}_{\mathrm{MEH}}=2.154 \mathrm{E}_{\mathrm{PMT}}$ & 0.464 \\
34.23 & $\mathrm{E}_{\mathrm{MEH}}=2.156 \mathrm{E}_{\mathrm{PMT}}$ & 0.464 \\
38.85 & $\mathrm{E}_{\mathrm{MEH}}=2.142 \mathrm{E}_{\mathrm{PMT}}$ & 0.467 \\
41.75 & $\mathrm{E}_{\mathrm{MEH}}=2.114 \mathrm{E}_{\mathrm{PMT}}$ & 0.473 \\
44.35 & $\mathrm{E}_{\mathrm{MEH}}=2.186 \mathrm{E}_{\mathrm{PMT}}$ & 0.457 \\
46.75 & $\mathrm{E}_{\mathrm{MEH}}=2.098 \mathrm{E}_{\mathrm{PMT}}$ & 0.477 \\
49.43 & $\mathrm{E}_{\mathrm{MEH}}=2.078 \mathrm{E}_{\mathrm{PMT}}$ & 0.481 \\
51.63 & $\mathrm{E}_{\mathrm{MEH}}=2.074 \mathrm{E}_{\mathrm{PMT}}$ & 0.482 \\
54.23 & $\mathrm{E}_{\mathrm{MEH}}=2.070 \mathrm{E}_{\mathrm{PMT}}$ & 0.483 \\
56.93 & $\mathrm{E}_{\mathrm{MEH}}=2.063 \mathrm{E}_{\mathrm{PMT}}$ & 0.485 \\
\hline
\end{tabular}

Figure 11. Recapitulation Curve of Menard's $\alpha$ factor

The recapitulation at table 5, 6, and 7 shows that the $\mathrm{E}_{\mathrm{MEH}}$ value is close to 2 times of EPMT, more precisely in the range of 2,01 to 2,20 times, while Menard's $\alpha$ factor which is generated from modeling is almost uniform, which 
ranges from 0.45 to 0.5 . These results are still included in the range of values that proposed by Briaud (1992) where Menard's a factor in rock samples ranges from $1 / 3$ to $2 / 3$.

Figure 11 shows that the recapitulation of EPMT and EFEM values at all testing points produces a very good linear line so that it can be used as a basis in determining the value of Menard's a factor on average. Menard's value $\alpha$ an average factor in limestone rock can be determined from the slope of the relationship curve that is equal to 0.47 .

The last analysis phase is to find out the relationship from the depth of the test point to Menard's a factor, in this case the depth point is represented by the value of the overburden load to be more representative of the influence given.

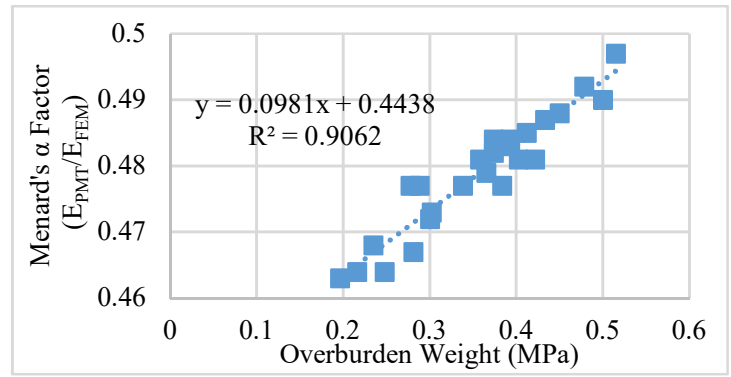

Figure 12 Relation Curve of Menard's $\alpha$ Factor and Overburden Weigh of point testing of PMT

Figure 12 shows that Menard's $\alpha$ factor increases with increasing overburden weight from the PMT test point which produces a slope angle of 0.0981 .

\section{CONCLUSION}

Some things that can be concluded from the results of this study are as follows:

1. The simulation results of rock sample behavior in PMT testing can be remodeled using FEM 2D quite well.

2. The elastic modulus value (E) in limestone sedimentary rocks can be predicted from the pressuremeter modulus $(\mathrm{EPMT})$ value with the equation $\mathrm{E}=\mathrm{EFEM}=2.1543 \mathrm{EPMT}-25.546$.

3. Menard's correction value a factor in limestone sedimentary rocks as large as 0.4685 .

4. Menard's value detection $\alpha$ factor of many boreholes can be applied as long as it has the same sample characteristics. In this study the result indicates Menard's $\alpha$ factor in limestone sedimentary rocks increases with the increase in the depth of the test point even though the increase is quite small.

\section{REFERENCES}

Abed Y., Bahar R., Dupla J.C., Bouzid DJ. A. (2013), Identification Of Granular Soils Strength And Stiffness Parameters By Matching Finite Element Results To Pmt Data, World Scientific.

Baguelin F., Jezequel J.F., Shields D.H. (1978), The Pressuremeter and Foundation Engineering, TransTech Publications, Clausthal-Zellerfeld, Germany.

Balachandran K. (2016), Statistical And Numerical Analyses Of Pressuremeter Tests In Glacial Tills, (Ryerson University, Canada.

Briaud J.L. (1992), The Pressuremeter, A.A. Balkema, Brookfield, VT, USA.

Gambin M.P. (1990), The History of Pressuremeter Practice in France, Proc. of 3rd International Symposium on Pressuremeters, Oxford University, Thomas Telford Limited, London; 5 - 24.

Levasseur S., Malecot Y., Boulon M., and Flavigny E. (2009), Statistical inverse analysis based on genetic algorithm and principal component analysis, Application to excavation problems and pessuremeter tests, International journal for numerical and analytical methods in geomechanics, 34: 471-491.

OYO Corporation (2006), Elastmeter-2 Manual (Oyo Corporation, Japan.

Rita O. (2008), Characterization Of Materials Behaviour By The Pressuremeter Test, Técnico Lisboa, Portugal.

Sedran G., Failmezger R.A., and Drevininkas A., (2013), Relationship between Menard EM and Young's E moduli for cohesionless soils, Proceeding of the 18th International conference on soil mechanics and geotechnical engineering, Paris 2013.

Yeung S.K., Carter J.P. (1987), Finite Elements Studies Of The Pressuremeter Test, Conference on Finite Element Methods in Engineering, Melboume. 